\title{
T.S.Eliot's Enquiry into the Limits of the Logos and the Shifting Cultural Paradigms
}

\author{
Dr. Piku Chowdhury \\ Assistant Professor, Satyapriya Roy College of Education, Kolkata
}

\begin{abstract}
The word and the world are no longer coeval. The modern world, near anarchic and totally absurd, emerges like a formidable fortress with complex labyrinths. The poet, the manipulator of words, struggles with the words themselves in quest of a possible exit. The verbal artifice erects a distinct world - confusing, abstract, and volatile; the entrapped intellect reacts in a desperate attack. Human thoughts are largely shaped by cultural influences, and cultural conventions and values embedded in language of the race or clan coordinate the multiple subsystems of a larger societal organization. The fact that language, thought and socio-cultural dimensions are inexplicably intertwined, in a way indicates a deterministic perspective. However, if language itself hovers at the edge of continual flux and indeterminacy, the socio-cultural context of relevance and interpretative exercises in any given context, assume kaleidoscopic variety and generate intriguing questions. Eliot's poetry and critical formulations continually question the validity of the word as an effective communicative medium and the perennially shifting linguistic bases of cultural paradigms.
\end{abstract}

[Key Words: logos, culture, limits, evolving]

\section{Introduction:}

If I succeed in mentally constructing a fortress from which it is impossible to escape, this imagined fortress either will be the same as the real one - and in this case it is certain we shall never escape from here, but at least we will achieve the serenity of knowing we are here, because we could be nowhere else - or it will be a fortress from which escape is even more impossible than from here - which would be a sign that here an opportunity of escape exists: we have only to identify the point where the imagined fortress does not coincide with the real one and then find it.

Italo Calvino, 't zero'

The word and the world are no longer coeval. The modern world, near anarchic and totally absurd, emerges like a formidable fortress with complex labyrinths. The poet, the manipulator of words, struggles with the words themselves in quest of a possible exit. The verbal artifice erects a distinct world - confusing, abstract, and volatile; the entrapped intellect reacts in a desperate attack. What is mockingly refracted in Joseph Heller's Catch 22 operates as a dominant concern in the modernist discourse. The words are strange forces, which continually create and predetermine, instead of recreating and presupposing the immediate world. Yossarian, the hero of Catch 22, invents a game of deleting words of letters at will and his apparently frenzied talk frequently hovers on the verge of a strange alien microcosm, engineered by the words. The projected world is incoherent, intimidating, and almost meaningless with a piercing jab of a mocking tone, continually asking "What difference would it make?" The readers are sucked into a whirlpool of randomness where the margins of the familiar and the absurd created by the words continually overlap. The mind gets trapped in a conceptual matrix and the connections between words, human perception and the immediate world are rendered essentially elusive, oblique and transient. The grotesque, scary strangeness deepens with an apparently playful mood implied in the utter carelessness of - "What difference does it make? Yossarian goes on deleting sections of personal letters and residential addresses whimsically:

Death to all modifiers, he declared one day, and out of every letter that passed through his hands went every adverb and every adjective. The next day he made war on articles. He reached a much higher plane of creativity the following day when he blacked out everything in the letters but $a$, an and the. That erected more dynamic intralinear tensions, he felt...Soon he was proscribing parts of salutations and signatures and leaving the text untouched...

When he had exhausted all possibilities in the letters, he began attacking the names and addresses on the envelopes, obliterating whole homes and streets, annihilating, entire metropolises with careless flicks of his wrist as though he were God.(p.8)

The humorous verbal devastations that recur throughout the discourse either turn to frustrated speechlessness or a deep-seated dilemma. Whether the words of any literary creation constitute a medium, a representational strategy for grasping the actuality or whether the entire world that can inhere in words is a textual finality, an artificial construct by the words themselves, remains a dilemma unresolved. Any flicker of 
faith in the representational or significatory stability of the words can perhaps never suffice and the intellect is bound to face the force of the whirlwinds that blow through any discourse. Italo Calvino in 'Cybernetics and Ghosts' attributes any tendency of clinging to a sense of finality as a defence mechanism that is deployed by the author against the baffling autonomy and almost demonic creative potential of the words:

Faced with the vertigo of what is countless, unclassifiable, in a state of flux, I feel reassured by what is finite, "discrete", and reduced to a system. Why is this? Does my attitude contain a hidden element of fear of the unknown, of the wish to set limits to my world and crawl back into my shell? Thus my silence, which was intended to be provocative and even profane, allows of the suspicion that, on the contrary, it is dictated by some kind of intellectual agoraphobia, almost a form of exorcism to defend me from the whirlwinds that literature so constantly has to face.(p.17)

Eliot's phases of hermeneutic faith in the word as manifestation of the transcendental Logos, that often impinge his perennial anxiety, probably record a perplexed mind's natural inclination to seek refuge in certitude. An acute awareness of the near opaque darkness in actuality remains and, contrary to what Calvino asserts in 'Cybernetics and Ghosts', the transient phases of retraction fizzle out into a renewed fortitude of confrontation. The very labyrinthine mazes of the strange fortress created by the autonomous words pose a challenge, and any challenge entails a sense of hope - a hope of victory through confrontation. Calvino, in his The Literature Machine, cites German poet and critic Hans Magnus Enzensberger, who brings out the potential of a newly reconstructed mode amidst the apparently closing in the sleet and hail of verbal imprecision:

"Every orientation", he writes, "presupposes a disorientation. Only someone who has experienced bewilderment can free himself of it. But these games of orientation are in turn games of disorientation. Therein lies their fascination and their risk. The labyrinth is made so that whoever enters it will stray and get lost. But the labyrinth also poses the visitor a challenge: that he reconstruct the plan of it and dissolve its power. If he succeeds, he will have destroyed the labyrinth; for one who has passed through it, no labyrinth exists."'(p.25)

Enzensberger adds that the moment a topological frame assumes the stature of a metaphysical structure, the dialectical balance is disrupted and the text appears to be demonstrating the sheer impenetrability of the world where fruitful communication is impossible; the labyrinth ceases to be an intriguing challenge to the human mind and "establishes itself as a facsimile of the world and of society". (p.26).

The challenge is to penetrate the surrounding opacity, to construct a perception that is way more complex than the baffling complexity of the immediate reality, in order to muster the efficiency of seeing through the deceiving mazes. The nature of the wrangle gets strangely complicated with the realization that that the ammunition is none other than the words - the same autonomous entities that are continually contriving an ever renewing web of relationships that herald what Calvino in 'Cybernetics and Ghosts' calls "the triumph of discontinuity, divisibility and combination over all that is flux"(p.9). The use of such weapons too is a rather difficult task with scant hope of any certain outcome. The words, like crystals, refract a blinding radiance, the nature of which cannot be easily predetermined. Calvino says in "Philosophy and Literature"-

words, like crystals, have facets and axes of rotation with different properties, and light is refracted differently according to how these word crystals are placed, and how the polarizing surfaces are cut and superimposed.(p.40)

Even when they are placed, the magnitude and the brilliance of the hard glitter is practically unpredictable, given that they have a rotational autonomy of their own. The continuous clash between the motile, blinding crystals and the intellect deploying them to penetrate the shrouding opacity, is eternal and it is this irreconcilability that keeps the journey alive; "only if we think of it as permanent but ever new", points out Calvino, "does it guarantee us that the sclerosis of words will not close over us like a sheet of ice". As Chomsky, citing Schelling in "Language and Freedom", had pointed out much earlier -

"Without the contradiction of necessity and freedom not only philosophy but every nobler ambition of the spirit would sink to that death which is peculiar to those sciences in which that contradiction serves no function". Without this tension between necessity and freedom, rule and choices, there can be no creativity, no communication, no meaningful acts at all.(p.88)

Moments of conviction in the emergence of a handful of relatively stable and pure resources of language guaranteeing an artistic transcendence of falsity, chaos and opacity, the emergence of that "one true sentence" that Hemingway mentions in A Moveable Feast, and Eliot anticipates in the form of the Word manifested in the voice of love, appear to be what Hugh Kenner calls a cloak of evasion in A Homemade World; such a tranquil phase of certitude is but a veil overlying a sense of utter vacuity. Yossarin in the concluding part of Catch 22 simply jumps - "he took off". The story ends here. The hero seems to simply disappear directly into the white spatial vacuum of the page, beyond the last line of the text. Interestingly enough, this final jump and the following blank whiteness of the page reveals the nature of the word in the discursive space - elusive, opaque, polysemous, nonreferential and essentially indeterminate. The vacuity and 
reader-directed open-endedness create a challenge, an urge to plunge into uncertainty to ferret out the dynamics of the combinatory multiplicity of the words in a text.

An apprehension of this spirit pervades Eliot's works. Even in overtly religious poems like 'Ash Wednesday', the last line declares a journey into the unknown- "And after this our exile". What one discovers in the process is a bewildering plurality of levels. The end is not perceptible, more significant perhaps is the sheer adventure of the progress. What is projected through the kaleidoscopic radiance of the glittering crystals of words, is not a chimerical illusion, but layers of reality that must be transcended in quest of the Word. As Calvino observes in 'Cybernetics and Ghosts', albeit in a different context, the distant shimmering of a light propels the lost child to continue his journey towards it, in an anticipation of a final moment the nature of which is perennially shrouded in darkness:

Did we say that literature is entirely involved with language, is merely the permutation of a restricted number of elements and functions? But is the tension in literature not continually striving to escape from this finite number? Does it not continually attempt to say something that it does not know, and that no one could ever know? ... the younger son gets lost in the forest, he sees a light in the distance, he walks and walks; the fable unwinds from sentence to sentence, and where is it leading? To the point at which something not yet said, something as yet only darkly felt by presentiment, suddenly appears and seizes us and tears us to pieces, like the fangs of a man-eating witch...the region that is still unexplored because there are as yet no words to enable us to get there.(p.18)

Eliot proceeds undaunted through the seductive layers of ever renewing combinations against the backdrop of an essentially motile and elusive discursive space, intensifying his poetic vision with prayer, fortitude, endurance, courage and a deep urge of going forth. On being asked about his destination, Harry in The Family Reunion answers:

That is still unsettled.

I have not yet had the precise directions.

Where does one go from a world of insanity?

Somewhere on the other side of despair.

To the worship in the desert, the thirst and deprivation,

A stony sanctuary and a primitive altar,

The heat of the sun and the icy vigil,

$\ldots$

It is love and terror

Of what waits and waits me...

In the course of this journey, phases of silence glitter like silent yet blinding crystals suspended in a smoky near opaque maze, luminescent with the potential of more intense communication. The hyacinth girl stands silent and the tiny water drops sparkle in her hair in The Waste Land, the slightly parted lips quiver in inaudible intensity in 'Marina', the pristine whiteness of silent bare bones dazzle with intimidating nakedness in 'Ash Wednesday' - all making the reader realize levels of messages otherwise beyond the reaches of human cognition. Analysing Dante's epic in 'Language in Paradise', Umberto Eco points out that the highest level of communication is perhaps nonverbal:

language will play a lesser role in Dante's travels. Even though he still talks with Saint Peter, Beatrice, or Saint Bernard, he is coming closer and closer to the site of the highest angelical hierarchies, and, as everybody knows, angels do not speak because they understand each other through a sort of instantaneous mental reading, and they know everything they are allowed to know (according to their rank) not by any linguistic intercourse but by watching the Divine Mind. At this point, as Dante says in the final canto of the Divine Comedy, language is unable to express what he sees(p.29).

The nature of the crisis deepens with the implied cultural equations with and influences on the continually shifting linguistic paradigms. Silence and confusion, luminescence and darkness, void and apparent fullness - the Eliotian discourse remains a chronicle of an exploration of such ambiguities and cultural problematic, the explorer continually energized by the ever renewing challenges of the meandering vistas.

\section{II}

Human thoughts are largely shaped by cultural influences, and cultural conventions and values embedded in language of the race or clan coordinate the multiple subsystems of a larger societal organization. The fact that language, thought and socio-cultural dimensions are inexplicably intertwined, in a way indicates a deterministic perspective. Benjamin Lee Whorf in 'A Linguistic Consideration of Thinking in Primitive Communities' observes,

The problem of thought and thinking in the native community is not purely and simply a psychological problem. It is quite largely cultural. It is moreover largely a matter of one especially cohesive aggregate of cultural phenomena that we call a language.(p.15) 
The problematic of a profoundly linguistic base of culture emerges as Whorf in 'The Relation of Habitual Thought and Behaviour to Language', jeopardizes the equal partnership of autocratic language and a dependent culture:

Which was first: the language patterns or the cultural norms? In main, they have grown up together, constantly influencing each other. But in this partnership, the nature of the language is the factor that limits the free plasticity and rigidifies channels of development in the more autocratic way. This is so because language is a system, not just an assemblage of norms (p.15)

If language itself hovers at the edge of continual flux and indeterminacy, the socio-cultural context of relevance and interpretative exercises in any given context, assume kaleidoscopic variety and generate intriguing questions. Habermas, in his theory of modernity in The Theory of Communicative Action, projects certain forms of rationalization that distinguishes between contexts articulated in terms of goals of human action and in terms of what he calls the 'steering media' like money and power that encode purposive and calculative rational dealings with values, leading to symbolic generalizations that tend to simplify communication. Such a duality of the communicative function of language suggests that the role played by language largely determines communications in the socio-cultural scenario. The turbulent modern times witness a powerful operation of the 'steering media' that tends to economize communicative efforts on strictly prosaic and utilitarian terms. Cultural values are discounted. What emerges is a surge of polyphonic discourse, limited and vacuous, being largely functional as the 'steering media' and not revelatory of what Habermas calls any 'context of relevance.' Chomsky's version of the modern complex predatory capitalist system, albeit placed in a different contextin 'Language and Freedom', gets close to the threat of the inane economized role of language that tends to undermine its significatory role:

It is incapable of meeting human needs that can be expressed only in collective terms, and its concept of competitive man who seeks only to maximize wealth and power, who subjects himself to market relationships, to exploitation and external authority, is antihuman and intolerable in the deepest sense. (p.89)

The assault of such a prosaic predatory culture on verbal modalities - and the general attitude for that matter, had prefigured in Eliot's 'Choruses from The Rock',VII:

Men have left GOD not for other gods, they say, but for no god; and this

has never happened before

That men both deny gods and worship gods, professing first Reason

And then Money, and Power, and what they call Life, or Race, or Dialectic.

The church disowned, the tower overthrown, the bells upturned, what have we to do

But stand with empty hands and palms turned upwards

In an age which advances progressively backwards?

they walk in the street proudnecked, like thoroughbreds ready for

Adorning themselves, and busy in the market, the forum,

And all other secular meetings:

Thinking good of themselves, ready for any festivity.

The hustle and economically motivated or power driven communicative endeavours only lead to a shocking communicative collapse; the world does not say anything significant, the verbal combinations continually 'stray' on a high-speed corridor:

What does the world say,

does the whole world stray in high-powered cars

on a by-pass way?

Again there often is a dramatic play of automatically evolving multiplicity of polyphonic linguistic patterns even in a single primitive cultural construct; a phenomenon that Bakhtin speaks of in The Dialogic Imagination. Bakhtin brings out the peculiar predicament of an illiterate peasant whose initial state of uncomplicated linguistic consciousness transforms to an anxious juncture of selecting his individual orientation among the plural linguistic patterns:

Thus an illiterate peasant, miles away from any urban centre, naively immersed in an unmoving and for him un shakeable everyday world, nevertheless lived in several language systems: he prayed to God in one language [Church Slavonic], sang songs in another, spoke to his family in a third and, when he began to dictate petitions to the local authorities through a scribe, he tried speaking yet a fourth language (the official-literate language, "paper" language). All these are different languages, even from the point of view of abstract socio-dialectological markers. But these languages were not dialogically coordinated in the linguistic consciousness of the peasant; he passed from one to the 
other without thinking, automatically:...as soon as a critical interanimation of languages began to occur in the consciousness of our peasant...then the inviolability and predetermined quality of these languages came to an end, and the necessity of actively choosing one's orientation among them began.(p.296)

If the overlapping and continual interplay of a startling plurality of language operative in a single socio-cultural framework, generate such an anxiety, what could be the linguistic anxiety and plight of the modernist American author facing an increasingly polygot world divested of local peculiarities and invested with multicultural influences that project stark identity crisis. Deeper folds of linguistic anxieties emerge as necessary corollaries of economic and political modernisations, a fact already indicated in the reference to the Habermassian 'steering mode'. Raymond Williams, in his Culture and Society, gives an apt description of the nature of this crisis in pointing out the increasing mobility, dislocation and centralization as agents to "convert what had been an experience of small minorities to what, at certain levels, and especially in its most active sites and most notably in the United States, could be offered as a definition of modernity itself'(pp.78-79). The natural linguistic standardization operative in a modern progressive economy, with its extension into the folds of a greater global industrialized domain, encountered a clash of localized peculiarities against a greater surge of new cultural dicta.

The Eliotian discourse registers the dramatic combat of the oppressed and oppressive qualities of language in a continually overlapping cultural multiplicity in an evolving economy. An acute linguistic and identity related crisis evolves with a dual force of freedom and fear: freedom from the oppression of the British English protocols, exploding in the form of the dialects of figures like Sweeney, and a refined sophisticated streak of insecurity, a fear of loss of a cultural and linguistic identity shown, for example, in a 'handful of dust'. In a letter cited by Lyndall Gordon in Eliot's New Life, Eliot expresses a fear that he might 'simply prove to be savage.' A sense of personal linguistic crisis extends into a concern for a rift in the English language itself, in two different cultures - a rift so great that it may give birth to two different languages altogether. In 'American Literature and Language', he points out:

We must carry the question further, and ask: is it probable that speech in England and speech in America are developing in such a way that we can predict the eventual division into two languages, so distinct that each country will provide one more foreign language for the school curriculum of the other?(p.48)

Evolution of new linguistic patterns coincides with the evolution of new cultures with the death of old ones. The concern apprehends an unimaginably vast socio-cultural change that generates enormous segregating forces in a linguistic framework:

Is such a transformation, for better or worse, of English into two distinct languages on the two sides of the Atlantic likely to take place?...if such a transformation should occur, it will be due to social, political and economic changes very different from anything that is happening now, and on such a vast scale that we cannot even imagine them.(pp.49-50)

Despite a hope of possible fusion of the distinct cultural facets of English language, Eliot concedes an intriguing cultural influence on the emergence of disturbingly new linguistic patterns that entails overt spatial connotations. "The literature of nineteenth century New England", Eliot points out "has its own particular civilized landscape and the ethos of a local society of English origin with its own distinct traits." The identity crisis enters new folds of anxiety with the concern about the originality of a literary text. If Edgar Alan Poe is treated as a typical American representative in the territory of continental literature, the fact remains that he failed to influence considerable number of American poets; the dilemma makes Eliot ask -

How is it that Poe can be chosen as a distinctively American author, when there is so little evidence that any American poet since Poe has written any differently than he would have wrOitten if Poe had never lived? (p.53)

What then is the true American identity? What linguistic pattern in a text can confer an approximation of a stable literary identity? Which cultural influences can hope to pin down the floating and overlapping verbal modules into the certitude of a stable profile?

Eliot identifies the nature of the crisis and his analysis seems to approximate a subtle deterritorialization in the form of linguistic universality, an element that transcends the superficial local traditional pressure to touch the realms of a basic cultural commonality. That is to say that a subtle convergence of identity operates with cultural and traditional distinctions. The surface description of territories in Mark Twain may be "strongly local", but his portrayal of the Mississippi in American English, elevates it to the status of the "universal river of human life." The foreigner must enjoy the cultural differences and yet appreciate a basic commonality in a work of art that possesses a "strong local flavour combined with unconscious universality":

The foreigner may at first be attracted by the differences: an author is found interesting because he is so unlike anything in the foreigner's own literature. But a vogue due to novel differences will soon 
fade out: it will not survive unless the foreign reader recognizes, perhaps unconsciously, identity as well as difference... Who could be more Greek than Odysseus? Or more German than Faust? Or more Spanish than archetype in the mythology of all men everywhere.(pp55-56).

A closer analysis raises questions about the interpretive mode of the foreign readers, the identity that they experience 'consciously' may essentially vary even in a given foreign culture. It is almost like the perception of form by a sailor and a camel driver approaching the city of Despina, described by Marco Polo in Calvino's Invisible Cities. Despina appears to be a gigantic ship or a camel's embroidered saddle to a camel driver and a sailor as it happens to be, depending on his unique position, both spatial and psychological. A single city is interpreted as two distinct cities in the vision of the foreigners:

Each city receives the form from the desert it opposes; and so the camel driver and sailor see Despina, a border city between two deserts.(p.15)

Italo Calvino's poignant portrayal of Kublai Khan's dilemma dramatizes the deeper fold of anxiety lurking beneath the apparent certitude in basic similarities despite cultural divides. Kublai hopes to truly possess his whole empire, a conglomerate of diverse cultures and languages, by attaining an accuracy of interpretation of the emblems Marco Polo used to depict the foreign territories. Though the previous descriptions portrayed the empire to Kublai through foreign languages that he interpreted in his own way, the decoding of Marco Polo's description assumes a different level altogether. Marco Polo's depiction, emblematic in essence, projected each land as labile grains of sand that create tantalizing profiles peculiar to the interpretive mind. Answering Kublai's anxious query, Marco Polo asserts that the emperor would himself become an emblem when he feels he has penetrated the enigma of each emblem. What emerges is an indication of an endless process, when foreignness of a verbal structure, despite its distinctiveness, tries to communicate, but the images created on a common point of intersection of the foreign language and identification, remain largely a labile product of a perennial interpretive process:

Sent off to inspect the remote provinces, the Great Khan's envoys and tax-collectors duly returned...the emperor is he who is a foreigner to each of his subjects, and only through foreign eyes and ears could the empire manifest its existence to Kublai. In languages incomprehensible to the Khan, the envoys related informations heard in languages incomprehensible to them: from this opaque, dense stridor emerged the revenues...But when the young Venetian made his report, a different communication was established between him and the emperor... The Great Khan deciphered the signs...obscure or obvious as it might be, everything Marco displayed had the power of emblems...In the Khan's mind the empire was reflected in a desert of labile and interchangeable data, like grains of sand, from which there appeared, for each city and province, the figures evoked by the Venetian's logogriphs..."On the day when I know all the emblems", he asked Marco, "Shall I be able to possess my empire, at last?" And the Venetian answered: "Sire,...On that day you will be an emblem among emblems."(p.19)

The linguistic-cultural possibilities are infinite, continually defying an absoluteness of significatory fixity and the interpretation of such linguistic-cultural codes remain a perpetual procedure. What Kublai interprets is not what Marco Polo actually conveys. As Eco observes in his 1990 Tanner Lectures, -

A text, once it is separated from its utterer (as well as from the utterer's intention) and from the concrete circumstances of its utterance (and by consequence from its intended referent) floats (so to speak) in the vacuum of a potentially infinite range of possible interpreatations.(p.41)

Eliot's early poem 'Melange Adultere de Tout' project a persona moving to different countries that jeopardizes any possible stability of identity and language. He is a professor in America, a journalist in England a petty banker in London, a philosopher in Netherland, erring perennially and yet gravitating towards Africa -a zone of infinite possibilities being totally free from civilization's definitive norms, in a strikingly light mood suggested by his apparently carefree "tralalala". In the poem, linguistic decorum is continually flouted as the juxtaposition of culturally distinct and distant terms dramatizes the interfusion of strong local peculiarities in the records of an essentially polygot globetrotter. His restive linguistic peregrination apparently ends in the "oasis of Africa", where racial cross-dressing represents his solitude and emancipation. Africa extends into a central vacuous zone, around which the other territories and linguistic variables play, finally gravitating towards that centre where restrictive linguistic standards melt into endless possibilities. The final depiction of the cenotaph projects an ultimate silent and empty abyss that operates as a sharp contrast to the linguistic dazzle of an essentially polygot modernist continually wavering between labile cultures, identities and vocabulary.

The Oxford Dictionary meaning of "cenotaph" implies a memorial erected in absence of the real body that may be elsewhere. One may show the scorched hills of Mozambique as his cenotaph; an intriguing proposition that suggests the possibility that no one knows with certainty where he rests, or whether he continues in his perennial forays. This suggests that the travel may be continuing and the suggested possibility betokens the absence of any significatory definiteness. Whether Eliot reaches the ultimate zone where the transcendental Logos shines out with a luminosity that dispels all doubt, cannot be asserted with exactitude, but 
the continual unfolding of significatory multiplicities, the inherent tensions and seductions, the intermittent bewilderment and perceptual clarity, the detachment and passionate desires that create a brilliant discursive design, are what constitute the essence of his compositions; that is the palpable reality of his works. As Calvino, aptly points out in his general discussion on literature -

The path we have followed - the levels of reality evoked by literature, the whole gamut of veils and shields - may perhaps stray off into infinity, may perhaps encounter nothingness...Perhaps it is in the field of tension between one vacuum and another that literature multiplies in depths of a reality that is inexhaustible in forms and meanings...literature does not recognize Reality as such, but only levels. Whether there is such a thing as Reality, of which various levels are only partial aspects, or whether there are only the levels, is something that literature cannot decide. Literature recognizes the reality of levels, and this is a reality (or "Reality") that it knows all the better, perhaps, for not having come to understand it by other cognitive processes. And that is already a great deal.(pp.120-121).

\section{References:}

[1] Bakhtin, M.M., 'Prehistory of Novelistic Discourse', The Dialogic Imagination, (ed.)M. Holquist, Austin: University of Texas Press, 1981.

[2] Calvino, Italo, 'Philosophy \& Literature', The Literature Machine (trans.) Patrick Creagh, London: Vintage Books, 1986.

[3] Calvino, Italo, 'Cybernetics and Ghosts', The Literature Machine (trans.) Patrick Creagh, London: Vintage Books, 1986.

[4] Calvino, Italo, Invisible Cities, (trans.) William Weaver, London: Vintage Books, 1997.

[5] Calvino, Italo. 'Levels of Reality in Literature', The Literature Machine (trans.) Patrick Creagh, London: Vintage Books, 1986.

[6] Chomsky, Noam, 'Language and Freedom', The Essential Chomsky (ed.) Anthony Arnove, New York: Penguin Books, 2008.

[7] Eco, Umberto, 'Interpretation and History', 1990 Tanner Lectures printed in Interpretation and Overinterpretation, (ed.) Stefan Collini, Cambridge: Cambridge University Press, 1992.

[8] Eco, Umberto, 'Language in Paradise', Serendipities: Language and Lunacy (ed.) William Weaver, London: Phoenix Paperback, 1998.

[9] Eliot, T. S., 'American Literature and Language', To Criticize the Critic and Other Writings, London: Faber and Faber.

[10] Eliot, T. S., 'Choruses from The Rock', Complete Poems and Plays of T. S. Eliot, London: Faber and Faber, 1969.

[11] Eliot, T. S., 'Conclusion', The Use of Poetry and Use of Criticism, London: Faber and Faber, 1964.

[12] Eliot, T.S., 'Little Gidding', Four Quartets, Complete Poems and Plays of T. S. Eliot, London: Faber and Faber, 1969.

[13] Eliot, T.S., The Family Reunion, Complete Poems and Plays of T. S. Eliot, London: Faber and Faber.

[14] Gordon, Lyndall, Eliot's New Life, New York: Farrar, 1988.

[15] Heller, Joseph, Catch-22, New Delhi: Light and Life Publishers, 1975.

[16] Italo, Calvino, The Literature Machine (trans.) Patrick Creagh, London: Vintage Books, 1986.

[17] Kenner, Hugh, A Homemade World: The American Modernist Writer, New York: Knopf, 1975.

[18] Whorf, Benjamin Lee, cited in Dialogue at the Margins: Whorf, Bakhtin and Linguistic Relativity by Emily A Schultz, Wisconsin: The University Of Wisconsin Press, 1990.

[19] Williams, Raymond, 'T.S.Eliot', Culture and Society: 1780-1950, New York: Columbia University Press, 1983. 